Original Research Paper

\title{
Assessment of Mothers Knowledge Regarding the Developmental Milestone among Children Under Two Years in Iraq
}

\author{
${ }^{1}$ Lujain Anwar Alkhazrajy and ${ }^{2}$ Enas Rifaat Salah Aldeen \\ ${ }^{1}$ Consultant Family Physician, Quality Assurance and academic Performance Unit, \\ Alkindy College of Medicine, University of Baghdad, Iraq \\ ${ }^{2}$ Family Physician, Alkarkh Health Directorate, Ministry of Health, Iraq
}

Article history

Received: 29-01-2017

Revised: 17-07-2017

Accepted: 14-09-2017

Corresponding Author: Lujain Anwar Alkhazrajy Consultant Family Physician, Quality Assurance and academic Performance Unit, Alkindy College of Medicine, University of Baghdad

E-mail: lujainalkhazrajy@gmail.com

\begin{abstract}
Assessing a child's growth through the observation of his/her developmental milestone requires a team effort, in which family plays an important role. To assess the knowledge of the Iraqi mothers regarding their children's developmental milestones of their children and to find out if there was any association between this knowledge and certain demographic variables. A cross sectional study, that extended for one year period with sample size of 400 mothers attending six primary health care centers in Baghadad for maternal and child health care. Data were obtained by using a questionnaire derived from the (developmental checklists birth to five 2012), it was composed of four domains of knowledge (motor, cognitive, language and social) in addition to the demographic information of the participated mothers. The data were then analyzed by SPSS version 22; Pearson's chi square test was used to used to detect the significance of association between categorical data accordingly and the mother's knowledge in each domain and every socio-demographic variable ( $p$ value $\leq 0.05$ was regarded significant). Regarding the age of the mothers, the majority were between $20-29$ years old $(40.5 \%), 70 \%$ of them were employed and the illiterate mothers constituted $(30.25 \%)$ of the study sample. Most of the mothers $(71.5 \%)$ stated that their experience was their main source of information. There was a significant association was observed between the mothers age and all four domains of knowledge, other variables (education level, source of information, employment, Number of children, Residence of family) showed different levels of association and most of the mothers had a limited knowledge regarding the cognitive domain.
\end{abstract}

Keywords: Milestone (MS), Cognitive Development, Motor Development

\section{Introduction}

It was observed that a good start at the beginning of the child's life helps to create an efficient person in the future society, because the first five-years in a child growth is a crucial period particularly for the development of the brain (Isaranurug et al., 2005).

Developmental milestones, for instance neck control sitting without support, crawling, standing, walking are generally understood to be vital stages of neurological development (Adolph and Berger, 2006; Gerber et al., 2010). Milestone" (MS) is a descriptive term used to denote a specific level of achievement (e.g., sitting without support) by the child at a particular stage. Since children vary in the progress of their development, milestones have a range of normal variation, meaning they are not fixed. Each child develops at its own unique pace and it may be difficult to predict exactly when a child will acquire a given skill. However the developmental milestones give a general idea of when to expect specific changes as a child grows older (ICUDCY, 2003).

Normative data exists for these milestones, for example, a child should be able to walk unaided at about one year, the years $0-3$ are critical in the formation of intelligence, personality and social behavior. Brain development before the age of one 
year is more rapid and intense than previously realized and the brain is much more vulnerable to environmental influences than suspected including nutrition, quality of interaction, care and stimulation (Tinajero and Loizillon, 2010).

Assessing a child's development is a team effort, in which family plays an important role. Mothers can identify the milestone development of infants by observations. A mother can tell the infant's doctor about any worries or concerns she may have. Pediatricians may also use developmental screening, which involves a series of questions and observations, aiming to qualify the child's ability to perform certain age-appropriate tasks and also provide a guide that can help in identifying infants who might be at risk for developmental delay (Mathew, 2012). Increasing knowledge regarding the developmental stages and milestones of infants and young children enhances parents' ability to foster realistic age-appropriate expectations for their children's behavior and has important implications on how parents can support their children's development with positive interactions, by using developmentally-appropriate discipline practices and providing cognitively stimulating environment. Researchers showed that mothers with more knowledge of their children's development are more likely to provide developmental stimulation to them and in turn have better developmental outcomes. Moreover, clinicians may rely on parents' knowledge about the health and development of their children for decision making, counseling and referrals. Widened knowledge about a childs' developmental milestones can lead to early detection of developmental delays and health issues (KCD, 2016).

Programmers that aim to enhance the health and/or development of children require baseline information on what caregivers know about and provide for their children so that the content and intensity of interventions can be individualized (Ertem et al., 2007). Studies about mother's judgment on Milestone development showed that there is still a sizable percentage of mothers who remain uninformed about the developmental milestone and its possible fatal consequences (CD, 2008).

Similarly in the World Health Organization (WHO) Multicenter Growth Reference Study that was conducted in different countries, Ghana, India, Norway, Oman and the United States, insignificant differences were found in attainment of key motor milestones (WHO, 2006). Despite uniformity in children's attainment of culturally independent developmental milestones, caregivers' knowledge of when children should acquire developmental skills appears to differ between cultures (Iqbal, 2012).

The populations of Western countries showed that there may be large differences in maternal knowledge and beliefs of young children's development between and within cultures (Ertem et al., 2007). Children are said to be developmentally delayed if they failed to reach specific developmental milestones at the expected age. A developmental delay occurs when a child has a delayed achievement of one or more of his milestones. It is important for mothers to recognize signs of developmental delay of the children in their care. Recognizing signs of cognitive delay (especially language and communication delays) can be even more difficult than identifying physical delays. Some children are naturally quiet, shy or slower to socialize with others, this does not necessarily mean that they are delayed, they may just have a calm temperament or personality (Mathew, 2012).

Missed milestones can be symptoms of developmental delays, which could be associated with more serious medical conditions. Parents who suspect missed milestones should make an appointment with their regular health care clinician and ask about the results of the last developmental screening test. Researchers showed that children who are identified and treated earlier have better outcomes in development, school performance and social skills (Romeo, 2016). In summary, knowledge of the child's development appears to be a component of skillful parenting. Evidence suggests that parents with poor knowledge of their children's development overestimate the rate of development, potentially leading to inappropriate expectations, impatience and intolerance. If parents understood where their children are along a developmental trajectory, they can tailor their expectations and provide equipment, stimulation and toys to match the child's "readiness" for a particular type of experience at each stage. While parents, mothers in particular, appeared to have some knowledge of factors that support optimal child's development, other evidences suggest that parental knowledge of children's development is limited in many areas (Rikhy et al., 2010).

\section{Rational of the Study}

This was the first population-based study that explored the maternal knowledge of children's milestone development in Iraq. Although health education sessions are well known at primary health care level, yet not one of them was directed towards this field. Awareness of these milestones for children under five year of age may be used to check the children's development, especially in remote areas. It is beneficial to determine at an early stage whether a developmental problem really exists and to clarify the range of the associated deficits. Then a complete service system is offered for early intervention

\section{This Study was Carried to}

- Assess the Iraqi mother's knowledge regarding children's developmental milestones

- To Find out if there is any association between this knowledge and certain demographic variables (education level, source of information regarding development, employment, Number of children, Residence of family) 


\section{Subject and Methods}

- Design: A cross sectional study.

- Setting: A convenient number of (six) primary health care centers in Baghdad, (three) in Alkarkh and (three) in Alrasafa districts, were chosen to conduct the study. These centers were chosen because they had nearly the same catchment area of the population

- Duration: The study period extended from 1st of July 2015 till the end of June 2016

- Sample size determination: The sample included all mothers who had attended the mentioned primary health care centers for maternal (antenatal and post natal) and child health care and were willing to participate in the research. The following assumption was used to calculate the sample Size required for the study:

$$
\begin{aligned}
& n=(Z \alpha / 2) 2(p(1-p)) / E 2 \\
& n=(1.96) 2(05(.5)) /(0.05) 2 \\
& n=384
\end{aligned}
$$

Where:

$$
\begin{aligned}
n= & \text { Number of sample } \\
\mathrm{Z} \alpha= & (1.96) 2 \text { for } 95 \% \text { confidence (i.e., } \alpha=0.05) \\
P= & \text { "Best guess" for prevalence }(=0.50) \\
e= & \text { Maximum tolerable error for the prevalence } \\
& \text { estimate (e.g. } \pm 0.05)
\end{aligned}
$$

\section{Distribution of Sample Size}

By systematic random sampling, were every other attending mother was chosen. The mothers were distributed as follows:

- Al-mansour primary health center: 72 participants

- Al-mustansryia primary health center: 70 participants

- Al-tobchy primary health center: 73 participants

- Bab al-muadham primary health center: 69 participants

- $\quad \mathrm{Al}$-adal primary health center: 70 participants

- Al-dhubad primary health center: 71 participants

\section{Pilot Study}

The study tool was pretested on 25 participants, who were excluded from the study sample to assess the reliability and applicability of the tool question are, it was used to test:

- The time needed to fulfill the questionnaire

- The quality of questions, concerning the information and language used

\section{Data Source}

Data were collected by a questionnaire which was derived from (developmental checklists birth to five) that was adapted and revised (2012) by the mid-state Early Childhood Direction Center, Syracuse university (New York, United States) (Shelov, 2009; HELP, 2016; Erikson, 1996; ASQ, 2010). With some modification, the primary form of the revised questionnaire was reviewed by 5 experts ( 2 consultant pediatricians, 2 consultant family physician and one community medicine specialist). The questions were made to elicit the socio-demographic information about the studied mothers (age of mothers, parity, residence, employment, educational level) and their knowledge about children developmental milestones which was divided into 4 categories:

- Motor development: Regarding gross and fine motor

- Cognitive and vision development

- Language and hearing development

- Social and emotional development

\section{Statistical Analysis}

\section{Descriptive Statistics}

Was presented in form of graphs.

\section{Scoring System}

By giving a score for each answer in a specific domain and then computing the median of answer scores for such domain, the following scoring system was adopted:

\section{Motor Development}

- 16-21 = Good knowledge

- 11-15 = Fair knowledge

- $10 \geq$ poor knowledge

\section{Cognitive Development}

- $\quad 11-15=$ Good knowledge

- 8-10 = Fair knowledge

- $7 \geq$ poor knowledge

\section{Language Development}

- Score 11-15 good knowledge

- Score 8-10 fair knowledge

- $\quad$ Score 7 and less poor knowledge

\section{Socio-Emotional Development}

- $\quad 11-15=$ good knowledge

- $8-10=$ fair knowledge

- $7 \geq$ poor knowledge

\section{Analytic Statistics}

Data were introduced into personal computer. SPSS version 22 was used in statistical analysis; chi square test 
was used to find out the significance of association between the mother's knowledge in each domain with each socio-demographic variables. $\mathrm{P}$ value $\leq 0.05$ was regarded as cut off point.

\section{Ethical Considerations}

- Approval of the scientific committee of Alkindy college of medicine for the research

- Permission was obtained from the Iraqi ministry of health by an Administrative order directed to PHCCs to facilitate the task of obtaining the information from the participants

\section{Results}

A total number of 400 mothers were included in this study, the main age group was between 20-29 years old $(40.5 \%), 70 \%$ of the mothers were employed and the illiterate mothers represented $(30.25 \%)$ of the participants. $62 \%$ of the mothers had less than 3 children and the mothers who lived in an urban area represented $84 \%$ of the studied group Table 1 . Regarding the source of the mother's information about developmental milestones of children, (71.5\%) of the respondents were dependant on their own experience with their previous children Fig. 1.

\section{Mother's age and Milestone Development Knowledge}

There was a significant association between the mother's age and their knowledge concerning children's development regarding motor, cognitive, language and hearing and social and emotional domains ( $\mathrm{p}$ values were $0.001,0.001,0.012,0.013$ respectively) as shown in Table 2.

\section{Occupation of Mothers and Milestone Development Knowledge}

A significant association was found between the mother's knowledge regarding motor milestone development of children and the mother's occupation ( $p$ value 0.03 ), on the other hand there was no significant association between the occupation of mothers and their knowledge regarding Cognitive, language and hearing and social and emotional aspects of developmental milestones ( $\mathrm{p}$ value $=0.624$, $0.768,0.285$ respectively) Table 3 .

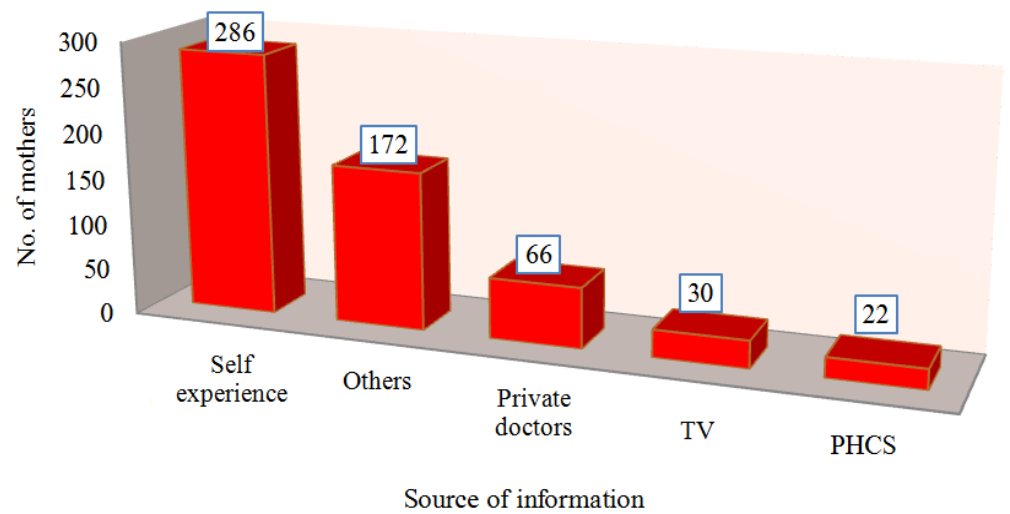

Fig. 1. Distribution of the sample regarding source of information about developmental milestones of children

Table 1. Socio-demographic characteristics of the mothers

\begin{tabular}{|c|c|c|c|}
\hline Variable & & No. & $(\%)$ \\
\hline Total number & & 400 & 100.00 \\
\hline \multirow[t]{4}{*}{ Age (year) } & $<20$ & 51 & 12.75 \\
\hline & $20-29$ & 162 & 40.50 \\
\hline & $30-39$ & 117 & 29.25 \\
\hline & $\geq 40$ & 70 & 17.50 \\
\hline \multirow[t]{2}{*}{ Occupation } & Not employed & 280 & 70.00 \\
\hline & Employee & 120 & 30.00 \\
\hline \multirow[t]{4}{*}{ Education } & Illiterate & 121 & 30.25 \\
\hline & Primary & 97 & 24.25 \\
\hline & Secondary & 93 & 23.25 \\
\hline & University & 89 & 22.25 \\
\hline \multirow[t]{3}{*}{ Parity } & $<3$ & 248 & 62.00 \\
\hline & $3-7$ & 127 & 31.75 \\
\hline & $>7$ & 25 & 6.25 \\
\hline \multirow[t]{2}{*}{ Residence } & Urban & 336 & 84.00 \\
\hline & Rural & 64 & 16.00 \\
\hline
\end{tabular}


Lujain Anwar Alkhazrajy and Enas Rifaat Salah Aldeen / American Journal of Applied Sciences 2017, 14 (9): 869.877 DOI: 10.3844/ajassp.2017.869.877

Table 2. Relation between age of mothers and their knowledge regarding developmental milestone

\begin{tabular}{|c|c|c|c|c|c|c|c|c|c|c|c|c|}
\hline \multirow[b]{2}{*}{ Variable } & & \multicolumn{2}{|l|}{ Total } & \multicolumn{2}{|l|}{$15-24$} & \multicolumn{2}{|l|}{$25-34 \mathrm{yr}$} & \multicolumn{2}{|l|}{$35-44 \mathrm{yr}$} & \multicolumn{2}{|l|}{$\leq 45$} & \multirow[b]{2}{*}{$P$ value } \\
\hline & & N 400 & $(\%)$ & $\mathrm{N}(70)$ & $17.5(\%)$ & $\mathrm{N}(162)$ & $40.5(\%)$ & N (117) & $29.25(\%)$ & $N(51)$ & $12.75(\%)$ & \\
\hline \multirow[t]{3}{*}{ Motor } & Poor & 164 & 41.0 & 45 & 64.3 & 59 & 36.4 & 50 & 42.7 & 10 & 19.6 & \\
\hline & Fair & 159 & 39.8 & 15 & 21.4 & 72 & 44.4 & 43 & 36.8 & 29 & 56.9 & 0.001 \\
\hline & Good & 77 & 19.2 & 10 & 14.3 & 31 & 19.1 & 24 & 20.5 & 12 & 23.5 & \\
\hline \multirow[t]{3}{*}{ Cognitive } & Poor & 220 & 55.0 & 48 & 68.8 & 89 & 54.9 & 61 & 52.1 & 22 & 43.1 & 0.001 \\
\hline & Fair & 106 & 26.5 & 22 & 31.4 & 35 & 21.6 & 30 & 25.6 & 19 & 37.3 & \\
\hline & Good & 74 & 18.5 & 0 & 0.0 & 38 & 23.5 & 26 & 22.2 & 10 & 19.6 & \\
\hline \multirow[t]{3}{*}{ Language } & Poor & 131 & 32.8 & 25 & 35.7 & 45 & 27.8 & 34 & 29.1 & 27 & 52.9 & \\
\hline & Fair & 247 & 61.8 & 43 & 61.4 & 110 & 67.9 & 74 & 63.2 & 20 & 39.2 & 0.012 \\
\hline & Good & 22 & 5.5 & 2 & 2.9 & 7 & 4.3 & 9 & 7.7 & 4 & 7.8 & \\
\hline \multirow[t]{3}{*}{ Social } & Poor & 210 & 52.5 & 36 & 51.4 & 82 & 50.6 & 66 & 56.4 & 26 & 51.0 & \\
\hline & Fair & 162 & 40.5 & 32 & 45.7 & 70 & 43.2 & 43 & 36.8 & 17 & 33.3 & 0.013 \\
\hline & Good & 28 & 7.0 & 2 & 2.9 & 10 & 6.2 & 8 & 6.8 & 8 & 15.7 & \\
\hline
\end{tabular}

Table 3. Association between mother knowledge regarding developmental milestones of children and occupation of mother

\begin{tabular}{|c|c|c|c|c|c|c|c|c|}
\hline \multirow[b]{2}{*}{ Variable } & & \multicolumn{2}{|l|}{ Total } & \multicolumn{2}{|c|}{ Employed } & \multicolumn{3}{|c|}{ Not employed } \\
\hline & & N 400 & $(\%)$ & $\mathrm{N}(120)$ & $30(\%)$ & $\mathrm{N}(280)$ & $70(\%)$ & $\mathrm{P}$ value \\
\hline \multirow[t]{3}{*}{ Motor } & Poor & 164 & 41.0 & 34 & 28.3 & 130 & 41.0 & 0.03 \\
\hline & Fair & 159 & 39.8 & 60 & 50.0 & 99 & 39.8 & \\
\hline & Good & 77 & 19.2 & 26 & 21.7 & 51 & 19.2 & \\
\hline \multirow[t]{3}{*}{ Cognitive } & Poor & 220 & 55.0 & 68 & 56.7 & 152 & 54.3 & 0.624 \\
\hline & Fair & 106 & 26.5 & 28 & 23.3 & 78 & 27.9 & \\
\hline & Good & 74 & 18.5 & 24 & 20.0 & 50 & 17.9 & \\
\hline \multirow[t]{4}{*}{ Language } & Poor & 131 & 32.8 & 40 & 33.3 & 91 & 32.5 & 0.768 \\
\hline & Fair & 247 & 61.8 & 72 & 60.0 & 175 & 62.5 & \\
\hline & Good & 22 & 5.5 & 8 & 6.7 & 14 & 5.0 & \\
\hline & Poor & 210 & 52.5 & 70 & 58.3 & 140 & 52.5 & 0.285 \\
\hline \multirow[t]{2}{*}{ Social } & Fair & 162 & 40.5 & 44 & 36.7 & 118 & 40.5 & \\
\hline & Good & 28 & 7.0 & 6 & 5.0 & 22 & 7.0 & \\
\hline
\end{tabular}

\section{Mother's Educational Level and Milestone} Development Knowledge

There was no association between the educational level of the mothers and their knowledge about motor function development ( $\mathrm{p}$ value 0.088), while a significant association was found between the educational level of the participant mothers and their knowledge of Cognitive and vision, Language and hearing and the social and emotional aspects of developmental milestone $(\mathrm{p}$ value $=0.037,0.016,0.001$ respectively) Table 4.

\section{Parity and Milestone Development Knowledge}

In this study, in which most of the mothers had less than three children, there was a significant association between parity and knowledge regarding motor, language and hearing developmental milestones $(\mathrm{P}$ value $=0.005,0.039$ respectively $)$, while no significant association was found between parity and knowledge of mothers concerning Cognitive and vision, Language and hearing developmental milestone ( $\mathrm{p}$ value $\mathrm{a}=0.269,0.69$ respectively) Table 5 .

\section{Residency of Mothers and Milestone Development Knowledge}

The study showed no significant association between the residency of the participated mothers and the knowledge regarding motor, cognitive and vision, language and hearing and social and emotional aspects of developmental milestone ( $\mathrm{p}$ value $=0.442$, $0.285,0.601,0.238$ respectively) Table 6 .

\section{The Mean of Mother's Knowledge}

The participated mothers exhibited a fair level of knowledge in the developmental milestones of their children, the highest knowledge (59\%) was for the child's language and hearing developmental milestone Table 7. 
Lujain Anwar Alkhazrajy and Enas Rifaat Salah Aldeen / American Journal of Applied Sciences 2017, 14 (9): 869.877 DOI: 10.3844 /ajassp.2017.869.877

Table 4. Association between mother knowledge regarding developmental milestone of children and educational level

\begin{tabular}{|c|c|c|c|c|c|c|c|c|c|c|c|c|}
\hline & & \multicolumn{2}{|l|}{ Total } & \multicolumn{2}{|l|}{ Illiterate } & \multicolumn{2}{|c|}{ Primary } & \multicolumn{2}{|c|}{ Secondary } & \multicolumn{3}{|c|}{ University } \\
\hline & & N 400 & $(\%)$ & $\mathrm{N}(121)$ & $30.25(\%)$ & N (97) & $24.25(\%)$ & N (93) & $23.25(\%)$ & $\mathrm{N}(89)$ & $22.25(\%)$ & P value \\
\hline \multirow[t]{3}{*}{ Motor } & Poor & 164 & 41.0 & 37 & 30.6 & 41 & 42.3 & 49 & 52.7 & 37 & 41.6 & 0.088 \\
\hline & Fair & 159 & 39.8 & 55 & 45.5 & 38 & 39.2 & 30 & 32.3 & 36 & 40.4 & \\
\hline & Good & 77 & 19.2 & 29 & 24.0 & 18 & 18.6 & 14 & 15.1 & 16 & 18.0 & \\
\hline \multirow[t]{3}{*}{ Cognitive } & Poor & 220 & 55.0 & 73 & 60.3 & 41 & 42.3 & 61 & 65.5 & 45 & 50.6 & 0.037 \\
\hline & Fair & 106 & 26.5 & 30 & 24.8 & 34 & 35.1 & 18 & 19.5 & 24 & 27.0 & \\
\hline & Good & 74 & 18.5 & 18 & 14.9 & 22 & 22.7 & 14 & 15.1 & 20 & 22.5 & \\
\hline \multirow[t]{4}{*}{ Language } & Poor & 131 & $32.80 \%$ & 38 & 31.4 & 42 & 43.3 & 29 & 31.2 & 22 & 24.7 & 0.016 \\
\hline & Fair & 247 & $61.80 \%$ & 75 & 62.0 & 49 & 50.5 & 64 & 68.8 & 59 & 66.3 & \\
\hline & Good & 22 & $5.50 \%$ & 8 & 6.6 & 6 & 6.2 & 0 & 0.0 & 8 & 9.0 & \\
\hline & Poor & 210 & $52.50 \%$ & 67 & 55.4 & 47 & 48.5 & 61 & 65.6 & 35 & 39.3 & \\
\hline \multirow[t]{2}{*}{ Social } & Fair & 162 & $40.50 \%$ & 48 & 39.7 & 44 & 45.4 & 30 & 32.3 & 40 & 44.9 & 0.001 \\
\hline & Good & 28 & $7.00 \%$ & 6 & 5.0 & 6 & 6.2 & 2 & 2.2 & 14 & 15.7 & \\
\hline
\end{tabular}

Table 5. The relation between mother knowledge regarding developmental milestone of children and parity

\begin{tabular}{|c|c|c|c|c|c|c|c|c|c|c|}
\hline \multirow[b]{3}{*}{ Variable } & & & & \multicolumn{6}{|c|}{ Number of children } & \multirow[b]{3}{*}{$P$ value } \\
\hline & & \multicolumn{2}{|l|}{ Total } & \multicolumn{2}{|l|}{$<3$} & \multicolumn{2}{|l|}{$4-7$} & \multicolumn{2}{|l|}{$>7$} & \\
\hline & & N 400 & $(\%)$ & $\mathrm{N}(248)$ & $62(\%)$ & 127 & $31.75(\%)$ & $\mathrm{N}(25)$ & $6.25(\%)$ & \\
\hline \multirow[t]{3}{*}{ Motor } & Poor & 164 & 41.000 & 106 & 42.7 & 55 & 43.3 & 3 & 12 & \\
\hline & Fair & 159 & 39.800 & 95 & 38.3 & 53 & 41.7 & 11 & 44 & \\
\hline & Good & 77 & 19.200 & 47 & 19.0 & 19 & 15.0 & 11 & 44 & 0.005 \\
\hline \multirow[t]{3}{*}{ Cognitive } & Poor & 220 & 55.000 & 142 & 57.3 & 67 & 52.8 & 11 & 44 & \\
\hline & Fair & 106 & 26.5 .0 & 68 & 27.4 & 30 & 23.6 & 8 & 32 & \\
\hline & Good & 74 & 18.5 .0 & 38 & 15.3 & 30 & 23.6 & 6 & 24 & 0.269 \\
\hline \multirow[t]{4}{*}{ Language } & Poor & 131 & $32.80 \%$ & 77 & 31.0 & 43 & $33.90 \%$ & 11 & 44 & \\
\hline & Fair & 247 & $61.80 \%$ & 163 & 65.7 & 73 & $57.50 \%$ & 11 & 4 & 0.039 \\
\hline & Good & 22 & $5.50 \%$ & 8 & 3.2 & 11 & $8.70 \%$ & 3 & 12 & \\
\hline & Poor & 210 & $52.50 \%$ & 133 & 53.6 & 65 & 51.2 & 12 & 48 & \\
\hline \multirow[t]{2}{*}{ Social } & Fair & 162 & $40.50 \%$ & 101 & 40.7 & 51 & 40.2 & 10 & 40 & \\
\hline & Good & 28 & $7.00 \%$ & 14 & 5.6 & 11 & 8.7 & 3 & 12 & 0.69 \\
\hline
\end{tabular}

Table 6. Association between mother knowledge regarding developmental milestone of children and residence of mothers

\begin{tabular}{|c|c|c|c|c|c|c|c|c|}
\hline \multirow[b]{2}{*}{ Variable } & & \multicolumn{2}{|l|}{ Total } & \multicolumn{2}{|l|}{ Urban } & \multicolumn{2}{|l|}{ Rural } & \multirow[b]{2}{*}{$\mathrm{P}$ value } \\
\hline & & N 400 & $(\%)$ & N (336) & $84(\%)$ & $\mathrm{N}(64)$ & $16(\%)$ & \\
\hline \multirow[t]{3}{*}{ Motor } & Poor & 164 & 41.0 & 140 & 41.7 & 24 & 37.5 & \\
\hline & Fair & 159 & 39.8 & 135 & 40.2 & 24 & 37.5 & \\
\hline & Good & 77 & 19.2 & 61 & 18.7 & 16 & 25.0 & 0.442 \\
\hline \multirow[t]{3}{*}{ Cognitive } & Poor & 220 & 55.0 & 180 & 53.0 & 40 & 62.5 & \\
\hline & Fair & 106 & 26.5 & 94 & 28.0 & 12 & 18.8 & \\
\hline & Good & 74 & 18.5 & 62 & 18.5 & 12 & 18.8 & 0.285 \\
\hline \multirow[t]{4}{*}{ Language } & Poor & 131 & 32.8 & 111 & 33.0 & 20 & 32.8 & \\
\hline & Fair & 247 & 61.8 & 205 & 61.0 & 42 & 65.6 & \\
\hline & Good & 22 & 5.5 & 20 & 6.0 & 2 & 3.1 & 0.601 \\
\hline & Poor & 210 & 52.5 & 182 & 54.2 & 28 & 43.8 & \\
\hline \multirow[t]{2}{*}{ Social } & Fair & 162 & 40.5 & 130 & 38.7 & 32 & 50.0 & \\
\hline & Good & 28 & 7.0 & 24 & 7.1 & 4 & 6.2 & 0.238 \\
\hline
\end{tabular}

Table 7. The distribution of the mean knowledge score of the mothers

Knowledge of participating mothers regarding developmental MS

\begin{tabular}{lllll} 
& Motor & Cognitive & Language & Social \\
\hline Mean & $(53 \%)$ & $(52 \%)$ & $(59 \%)$ & $(51 \%)$ \\
\hline
\end{tabular}




\section{Discussion}

Developmental milestones are sets of functional skills or age-specific tasks that most children can do at a certain age range. Pediatrician uses milestones to help check how the child is developing. Although each milestone has an age level, the actual age when a normally developing child reaches that milestone can vary quite a bit. Every child is unique (UMHS, 2016).

\section{Mothers Source of Information Regarding Milestones of Children}

Regarding the source of mother's information about the developmental milestones of children, $(71.5 \%)$ of the mothers depended on their experience with their previous children and with the present child as a source of their information, while only $(16.5 \%)$ obtained their knowledge from the doctors and $(5.5 \%)$ from the primary health care centers. These results were inconsistent with those mentioned in a cross sectional study by Rikhy et al. (2010) were it revealed that over $90 \%$ of parents who accessed doctors or pediatricians as a source of information and nearly $65 \%$ of parents that sought information from physicians were very satisfied. In addition, it is also different from those results registered by Deepika et al. (2014) study in 2014 in which the parents were most likely dependant on doctors/pediatricians, books and nurses as sources of their knowledge. These differences may be due to poor doctor-patient relationships in primary health care practice in Iraq. Moreover, the shortage in number of physicians in Iraq render it difficult to spend extra time with the mothers educating them about the children's developmental milestones (Deepika et al., 2014).

\section{Knowledge of Cognitive and Vision Development}

Employed mothers, especially those with higher education, have a good motor, cognitive and vision development knowledge, which was similar to the results of the Turkish study by Ertem et al. (2007) The study showed that the mean score of the sample had a satisfactory knowledge level. The score was arbitrarily fixed at $(50 \%)$. The results revealed that most of the mothers were knowledgeable about physical care activities but has limited awareness in cognitive care field, implied by the finding of a poor mean knowledge of Cognitive development in this study. This is in concordant with Jordanian study by Safadi et al. (2015).

\section{Association between Mother Knowledge Regarding} Developmental Milestone of Children and age

The present study showed that there was a significant association between the mother's age and her knowledge regarding developmental milestone of children (motor, cognitive, language and social) which is the same result reached by Ertem et al. (2007).
Association between Mother Knowledge Regarding Developmental Milestone of Children and Occupation of Mothers

The current study showed that there was no significant association between mother's knowledge regarding cognitive and vision development and mother's occupation, the same apply for Language and hearing development knowledge. A significant association was found between the mother's knowledge regarding motor developmental milestone of children and the mother's occupation, the good achievements were found among employed mothers. This was inconsistent with Malathi (2012) study, in which there was a significant association between housewife mothers and knowledge regarding motor development.

\section{Association between Mother's Knowledge Regarding Developmental Milestone of Children and Educational Level}

It had been found that there was a significant association between mother's motor, cognitive, language and social knowledge scores and both the level of education and mother's ages, similar results was found in a study done by Ertem et al. (2007). A similar finding was found in a study done in ryiadh by (Moawed and Saeed (2000) were a statistically significant correlation was found between mother's knowledge and their practices during infants' diarrheal episodes and mother's age and education. It was also similar to a study done in Jeddah by (Shawky et al., 2001) who reported on the effect of maternal education on the rate of childhood handicap and found that the risk of having a handicapped child declined sharply with there is increase in the level of maternal education. On the other hand the study result was inconsistent with a study done by Jan et al. (2000; Shawky et al., 2001) which revealed that there was no correlation between parents' level of education and safety practices, also inconsistent with (Al-Ayed, 2010) were no association was evident between mother's knowledge of child health related matters and level of education, age or number of children. One possible explanation of this results' variety could be the use of different research methodology (sample selection, data gathering and others).

\section{Association between Mother Knowledge Regarding Developmental Milestone of Children and Parity}

Regarding parity, there was a significant association between mother's knowledge on developmental milestone of children in motor, hearing and language fields and the number of delivered babies, which was different from study done in 2015 were no significant association was found (Safadi et al., 2015). 
Association between Mother Knowledge Regarding Developmental Milestone of Children and Residence of Mothers

There was no association between the residency of the mother and their knowledge regarding milestone, which was the same finding by Rikhy et al. (2010).

\section{Conclusion}

Older aged mothers with higher level of education, employed and with high number of parity have a good knowledge about children's developmental milestones. Many mothers were knowledgeable about motor development but had limited knowledge in cognitive milestone and the majority of mothers depended on their experience with their previous children and with the present child as the main source of their information.

\section{Acknowledgment}

The authors gratefully acknowledge Associate Prof. Dr. Ali Abulrazaq for his scientific advices in evaluating the study questionnaire. Thanks to all the medical staff of the primary health care centers for their help and support in completing this research. Finally great appreciation to all Iraqi mothers, who were interested in participating in this study and for their patience and cooperation.

\section{Author's Contributions}

Lujain Anwar Alkhazrajy: Establishing research question, Designed the research plan and organized the study, Reviewing the article critically for significant intellectual content, Author gave final approval of the version to be submitted and any revised version.

Enas Rifaat Salah Aldeen: A cquisition and collection of data, Analysis and interpretation of data, drafting the article. Author gave final approval of the version to be submitted and any revised version.

\section{Ethics}

- Approval of the scientific committee of Alkindy college of medicine for the research

- Permission was obtained from the Iraqi ministry of health by an Administrative order directed to PHCCs to facilitate the task of obtaining the information from the participants

\section{References}

Adolph, K.E. and S.E. Berger, 2006. Motor development. Handbook Child Psychol., 6: 161-213.

Al-Ayed, I.H., 2010. Mother's knowledge of child health matters: Are we doing enough? J. Family Community Med., 1: 22-22
ASQ, 2010. ASQ and ASQ-SE-Paul H. Brookes Publishing Company.

CD, 2008. Infant social development research study. Child Dev.

Deepika, D., J.T. Khushlata and S. Kamla, 2014. A study to assess the knowledge of mother's regarding developmental milestones of infants. Int. J. Curr. Res., 6: 7524-7528

Erikson, J., 1996. The Infant-Toddler Developmental Assessment (IDA): A family-centered trans disciplinary assessment process. New visions for the developmental assessment of infants and young children. Washington, DC: Zero to Three: The National Center for Infants. Toddlers Families.

Ertem, I.O., G. Atay, D.G. Dogan, A. Bayhan and B.E. Bingoler et al., 2007. Mother's knowledge of young child development in a developing country. Child Care Health Dev., 1: 728-37.

Gerber, R.J., T. Wilks and C. Erdie-Lalena, 2010. Developmental milestones: Motor development. Pediatrics Rev., 31: 267-77.

HELP, 2016. Hawaii Early Learning Profile (HELP)Vort Corporation. http://www.vort.com/HELP-0-3years-Hawaii-Early-Learning-Profile

ICUDCY, 2003. International corner UNICEF and Disabled children and youths. Disability World

Iqbal, H., 2012. Parenting and child development in multiethnic Britain: A study of British Indian, British Pakistani and non-immigrant White families living in the UK. PhD Thesis, University of Cambridge.

Isaranurug, S., W. Thongnop, S. Nanthamongkolchai and S. Singhaniyom, 2005. Capacity building of mothers on promoting infant development. $3: 37-44$

Jan, M.M., F.H. Hasanain and A.A. Al-Dabbagh, 2000. Infant and child safety practices of parents. Saudi Med. J., 21: 1142-1146.

KCD, 2016. Knowledge of child development.

Malathi, S., 2012. Mother's knowledge on growth and development of their children between 0-3 years in selected rural area. Growth, 14: 1-4.

Mathew, M.L., 2012. A study to assess the effectiveness of structured teaching programme on influence of prenatal factors on growth and development of newborn among primi-gravida mothers attending selected hospitals in Bangalore. Rajiv Gandhi University Health Sci.

Moawed, S.A. and A.A. Saeed, 2000. Knowledge and practices of mothers about infants' diarrheal episodes. Saudi Med. J., 21: 1147-1151.

Rikhy, S., S. Tough, B. Trute, K. Benzies and H. Kehler et al., 2010. Gauging knowledge of developmental milestones among Albertan adults: A cross-sectional survey. BMC Public Health, 8: 1-1.

Romeo, A., 2016. Tracking Your Baby's Milestones. Lamaze Parents. 
Safadi, R.R., M. Ahmad, O.S. Nassar, S.A. Alashhab and R. AbdelKader et al., 2015. Jordanian mother's knowledge of infants' childrearing and developmental milestones. Int. Nursing Rev., 63: 50-59 63. DOI: 10.1111/inr.12185

Shawky, S., W.M. Milaat, B.A. Abalkhail and N.K. Soliman, 2001. Effect of maternal education on the rate of childhood handicap. Saudi Med. J., 22: 39-43.

Shelov, S.P., 2009. Caring for Your Baby and Young Child: Birth to Age Five. 1st Edn., Bantam, New York, ISBN-10: 0553386301, pp: 892.
Tinajero, A.R. and A. Loizillon, 2010. The review of care, education and child development indicators in early childhood. United Nations Educational, Scientific Cultural Organization, Paris.

UMHS, 2016. Developmental milestones: Your child University of Michigan health system.

WHO, 2006. WHO motor development study: Windows of achievement for six gross motor development milestones. Acta Paediatrica, 450: 86-95. 